\title{
ÀS FACES DO FANTÁSTICO - "O GATO” DE MURENA E SUAS POSSIVEIS INTERPRETAÇÕES
}

\author{
Ana Flávia Salvi ${ }^{1}$ \\ Nerynei Meira Carneiro Bellini²
}

RESUMO: Este artigo tem por objetivo analisar a narrativa "O Gato", do autor argentino H.A. Murena na perspectiva da literatura do fantástico. Por meio dessa análise, pretende-se levantar as características estéticas do texto, a fim de estabelecer as modalidades específicas, originárias da vertente do fantástico e suas múltiplas possibilidades de interpretação. Ademais, far-se-á um retrato da figura do gato na literatura. Para tanto, serão retomados pressupostos teóricos afins dos estudiosos Todorov, Ceserani, Bella Jozef, Roas, dentre outros.

PALAVRAS-CHAVE: Fantástico. Vertentes. Gato.

\section{INTRODUÇÃO}

A irrealidade é condição da arte.

J. L.BORGES

A literatura fantástica se destaca dos demais gêneros literários pelo seu poder de interpretação, esse tipo de texto nos proporciona uma gama de análises,que variam conforme o contexto social e época de seu leitor, Todorov diz que o fantástico é um caso particular da categoria mais geral da visão ambígua.

Na América Latina, essa construção literária ganhou força na época pós $1^{\text {a }}$ guerra mundial, foi quando o homem hispano-americano resolveu desmistificar os conceitos europeus sobre a América Latina, mostrando uma realidade mais intensa e profunda, para isso ele se utilizou da criação de mundos fantásticos. Não podemos negar que foi justamente neste período a época de ouro da literatura hispano-americana, onde as vanguardas advindas da Europa e os movimentos pós-guerra influenciaram a criação de um terreno fértil para a construção de uma literatura única, uma literatura latina, abandonando a visão eurocêntrica, exótica adotada até então pelos escritores. Nesse terreno fértil, floresceram escritores como Casares, Borges, Ocampo, Carpentier e, mais tarde, Cortázar, García Márquez e muitos outros.

Héctor A. Murena nasceu em Buenos Aires em 1923, foi um escritor, poeta e ensaísta. Sua primeira obra publicada foi Primer Testamento, em 1946, uma coletânea de contos. Foi o primeiro autor argentino a fazer traduções de

\footnotetext{
${ }^{1}$ Graduada em Letras e Literatura pela Universidade Estadual do Norte do Paraná, UENP. Email: anaflavia_s94@hotmail.com

${ }^{2}$ Doutora em Letras pela Universidade Estadual Paulista Júlio de Mesquita Filho, UNESP. Email: nerynei@uenp.edu.br
} 
Theodor Adorno e Walter Benjamin, fato que marcou a sua construção poética durante toda vida, suas obras causavam irritação, polemica e desconforto, o que fez com que a crítica nomeasse sua forma única de escrever, chamando de Murenismo.

\begin{abstract}
Até este ponto, tentamos trabalhar especificamente com o pensamento original e, se quiser, antecipado de Hector $\mathrm{A}$. Murena em relação à sua leitura e tradução precoce de Adorno e Benjamin, sua vertente mística e telúrica, seu complexo vínculo com os membros das revistas Sur e Contorno, entre outros aspectos. Por este movimento sempre deslocado e eclético no campo cultural argentino, todos os textos que Murena publicou na vida causaram, em todos os âmbitos, moléstia, irritação, polêmica. Esse desconforto, desconfiança ou miopia intelectual levaram à construção de uma leitura hegemônica de seus textos como espiritualista e, desse modo, acabou reduzindo toda a produtividade que seus textos propunham. É por isso que o que a crítica chamou - e continua chamando - "murenismo", ao seu determinismo telúrico e seu espiritualismo, está longe de descrever em toda a sua densidade e complexidade seu pensamento. (DJAMENT, 2007, p. 85) ${ }^{3}$.
\end{abstract}

O Conto "O gato", foi publicado na Antologia da Literatura fantástica, organizada por Borges, Casares e Ocampo em1940,é narrado em terceira pessoa, possuindo um narrador onisciente, a história se inicia com o personagem principal, não nomeado, indo embora, deixando uma pessoa querida. No meio do caminho, um gato começa a segui-lo e mesmo o espantando, o animal continua perseguindo-o. Homem e gato chegam a uma pensão e ali se alojam. De início, os hospedes demonstram repulsa ao bichano. $O$ narrador começa a descrever a rotina do personagem na pensão, com suas saídas, enquanto o gato só ficava dormindo. Em determinado momento o homem resolve se inspirar no animal e não mais sair do quarto, só ficar ali, comendo, dormindo como o felino fazia, sem se preocupar com a vida. No final da narrativa vemos a pessoa que ele abandonou indo ao seu encontro, mas ele, enclausurado em seu quarto, não consegue nem mais falar, a pessoa o chama e o personagem só consegue miar, tendo então se transformado em um gato.

\footnotetext{
${ }^{3}$ Hasta aquí intentamos trabajar específicamente el pensamiento original y, si se quiere, anticipatorio de Héctor A. Murena en relación con su lectura y traducción temprana de Adorno y Benjamín, su vertiente mística y telúrica, su complejo vínculo con los miembros de las revistas Sur y Contorno, entre otros aspectos. Por este movimiento siempre desplazado y ecléctico dentro del campo cultural argentino, todos los textos que Murena publicó en vida causaron, en todos los ámbitos, molestia, irritación, polémica. Esta incomodidad, desconcierto o miopía intelectual hicieron que se construyera una lectura hegemónica de sus textos en clave espiritualista y, de este modo se terminó cercenando toda la productividad que sus textos proponían. Es por eso que lo que la crítica llamó - y sigue llamando - "murenismo", apelandoa su determinismo telúrico y a su espiritualismo, está lejos de describir en toda su densidad y complejidad su pensamiento.
} 


\section{DESENVOLVIMENTO}

O conto em questão faz parte da literatura dita como insólita na qual seres e fatos, próprios do enredo, remetem a eventos incomuns, impossíveis de sucederem na realidade empírica, conforme as leis naturais.O termo insólito é utilizado como forma de abranger os vários subgêneros que compõem esse tipo de literatura como o fantástico, o maravilhoso, o realismo mágico, entre outros. Neste trabalho, pretendemos nos utilizar das relações e especificidades dos termos fantástico e realismo maravilhoso.

Todorov, um dos precursores dos estudos sobre o fantástico literário, em seu livro Introdução a Literatura Fantástica, publicado originalmente em 1939, discorre sobre o formato da narrativa fantástica do século XIX, explicando como ela ocorre.A literatura fantástica,sistematizada por ele, caracteriza-se,inicialmente, pela hesitação, do personagem e do leitor diante do estranho, do inexplicável. $\mathrm{O}$ fantástico é a hesitação experimentada por um ser que só conhece as leis naturais, face a um acontecimento aparentemente sobrenatural. (TODOROV, p.31, 2012)

Todorov diz, em seus estudos, que o fantástico também é dependente da maneira como se lê, não se configurando em uma leitura poética e nem alegórica.

\footnotetext{
Primeiro, é preciso que o texto obrigue o leitor a considerar o mundo das personagens como um mundo de criaturas vivas e hesitar entre uma explicação natural e uma explicação sobrenatural dos acontecimentos evocados. [...] é importante que o leitor adote uma certa atitude para com o texto: ele recusará tanto a interpretação alegórica quanto a interpretação "poética". (TODOROV, 2012, p.39).
}

Diante dos eventos sobrenaturais evocados nos textos identificamos a premissa do fantástico, a partir do momento em que, frente ao sobrenatural, optamos por um caminho de interpretação que justificaria o evento, abandonamos o fantástico e entramos nas suas subcategorias que são: o maravilhoso e o estranho.

Como já foi dito, o fantástico ocorre quando, no texto, existe a presença de um fenômeno sobrenatural, que rompe as leis do mundo real, mas esse não é explicado, não ocorre o desenrolar do fato na trama, apesar de acontecer o questionamento por parte da personagem, o enredo termina sem explicar se 0 
fato foi real ou imaginado e, portanto, irreal. Já, no maravilhoso, as leis do mundo real podem ser rompidas, porque naquele mundo construído as premissas podem ser outras, independem das leis naturais, podemos citar como exemplos: Os 7, de André Vianco, Senhor dos anéis, de Tolkien, Alice no país das Maravilhas, de Lewis Carroll. No estranho, ponto de nosso estudo, os fenômenos sobrenaturais possuem uma explicação lógica, pautada na ciência ou afins.

[...] por necessidade de explicar o fantástico, existe também o estranho. Nas obras que pertencem a este gênero, relatam-se acontecimentos que podem perfeitamente ser explicados pelas leis da razão, mas que são de uma maneira ou de outra, incríveis, extraordinários, chocantes, singulares, inquietantes, insólitos e que, por esta razão, provocam na personagem e no leitor reação semelhante àquela que os textos fantásticos nos tornaram familiar. (TODOROV, 2012, p. 53).

Ele continua dizendo:

O estranho realiza, como se vê, uma só das condições do fantástico: a descrição de certas reações, em particular do medo; está ligado unicamente aos sentimentos das personagens e não a um acontecimento material que desafie a razão [...] (TODOV, 2012, p 53).

Tendo essas explicações como base para se entender o estranho na literatura do fantástico, podemos iniciar uma discussão acerca do conto "O gato", de Hector Murena, fazendo um estudo sobre a linguagem presente no texto.

A linguística é uma ciência porque se constitui num conjunto sistemático de factos e de teorias para o estudo da linguagem e das línguas. (CHARLIER, p.30, 1981). É composta por várias correntes que tentam delimitar o conceito de língua e linguagem. Pensando em uma dessas concepções, a neurolinguística, podemos entender a linguagem como algo inerente a todos os seres vivos, um instinto, mesmo que primitivo de comunicação. Já a língua é algo único dos seres humanos, adapta-se aos seus usuários e pode variar de região para região, sendo assim, viva e dinâmica. A língua é o que nos difere dos outros animais, pois,por meio dela, podemos expressar muito mais que anseios primitivos, ou seja, podemos racionalizar e socializar pensamentos e sentimentos, assim, podemos dizer que é a língua que nos torna humanos.

A partir da premissa da língua como um conjunto de códigos ativos passíveis de mudança segundo o ambiente onde está inserido, entendemos a metamorfose ocorrida no conto "O gato", de Hector Murena, como uma perda da 
capacidade da fala, uma regressão a um instinto primitivo. Dois pontos que justificam essa concepção é o fato do personagem, em determinado momento da obra, ter abandonado o convívio com os seres humanos, ficando recluso em seu quarto, tendo o gato como o único companheiro. Também é dito na obra que ele resolverá imitar o estilo de vida do bichano. Na produção, o decorrer do tempo não é claro, não sabemos quantos dias se passaram desde que o personagem chegara à pensão e nem quando resolvera viver como um gato. Mas,inferindo que tenha sido em um processo longo, concebemos que, como o personagem há muito não se utilizava de sua capacidade de fala para manter contato com as pessoas, aos poucos foi se esquecendo de como comunicar-se verbalmente e aprendendo a se comunicar de outras maneiras, assimilando para si a linguagem, expressões e atitudes felinas. Quando a pessoa, que ele abandonou, foi ao seu encontro e o chamou, ocorreu o que chamamos de atrito linguístico, como ele havia perdido o hábito da utilização da própria fala e agora se expressava de outra maneira, no momento de desespero, de ansiedade não conseguiu resgatar aquilo que já sabia, então acabou miando.

Apesar do estudo realizado até agora, basilar para a categoria do fantástico enquanto norteadora dos feitos estéticos, a teoria de Todorov não abarca certos eventos literários suscitados em obras recentes, do século $X X$, mais especificamente, as produções latino-americanas. Nessas obras não encontramos algo que vai de encontro ao apresentado por Todorov, ou seja, não existe a presença da hesitação proposta inicialmente, pois o personagem é passivo, diante da anormalidade.

\begin{abstract}
O fantástico, para Todorov, é a percepção particular de acontecimentos estranhos. Sua teoria tem utilidade indiscutível na caracterização do gênero. Mas no caso hispano-americano, sua premissa não tem razão de ser: "La foi absolue comme l'incrédulité totale nous méneraint hors du fantastique; c'est l'hesitation qui lui donne vie ${ }^{4 \prime}$ (JOZEF,1968, p.198).
\end{abstract}

Nesta linha de pensamento, o conto de Murena, não se enquadra na teoria proposta por Todorov, pois em nenhum momento percebemos a hesitação diante do sobrenatural por parte do narrador ou do personagem. A possível transformação do homem em animal é quase tida como uma consequência pelo

\footnotetext{
${ }^{4} \mathrm{~A}$ fé absoluta como a incredulidade total nós afasta do fantástico, é a hesitação que lhe dá vida. (Tradução nossa).
} 
fato do protagonista só dormir e comer e de ter assimilado o estilo de vida do gato. No mundo proposto no texto, não é estranho se metamorfosear, é algo que pode ser real, concebível, assim como em Kafka, em sua novela $A$ metamorfose, na qual o personagem se transforma em um inseto gigante, mas não provoca nenhum assombro. Para Todorov,essa obra de Kafka rompe com o fantástico tradicional, pois, nela, o escritor percorre o caminho oposto ao recorrente, assim, ele, parte do sobrenatural para chegar ao natural, premissa que também rodea as narrativas latino-americanas. Bella Jozef afirma que a generalização desse universo, unida à facticidade e à necessidade, transforma a obra de Kafka em fantástica.

O termo realismo maravilhoso ou chamado também de realismo mágico, nasceu exatamente para nomear a literatura que estava sendo produzida na América hispano-americana, onde a divisão entre o fantástico e o maravilhoso não se fazia clara.

Assim, pois, o realismo maravilhoso se distingue, por um lado, da literatura fantástica, posto que não se produz esse enfrentamento sempre problemático entre 0 real e o sobrenatural que define 0 fantástico, e, por outro, da literatura maravilhosa, ao ambientar suas histórias em um mundo cotidiano mesmo em seus mínimos detalhes ${ }^{5}[\ldots]$ (ROAS, 2001, p.12).

Jozef também afirma que o conceito de realismo maravilhoso está ligado a modelos regionalistas-realistas, que se estenderam até os anos 30 ou 40 . Com o surrealismo, a fantasia incorpora-se como elemento estruturante, além de uma forma de reação à condição alienante do homem frente ao espaço exterior. $O$ fantástico na literatura hispano-americana não é uma situação anormal, ele é aceito e passa a ser uma regra.

Como já foi dito anteriormente, no texto ocorre a metamorfose do personagem em gato, a metamorfose de homem para animal, apesar de não conseguirmos provar, no decorrer da narrativa, se o personagem realmente se transformou em um gato ou tudo foi fruto da sua imaginação ou condição, como já foi dito, na literatura a transformação de seres humanos em animais e outros

\footnotetext{
${ }^{5}$ Así pues, el <<realismo maravilloso >> se distingue, por un lado, de la literatura fantástica, puesto que no se produce ese enfrentamiento siempre problemático entre lo real y lo sobrenatural que define a lo fantástico, y, por otro de la literatura maravillosa, al ambientar las historias enun mundo cotidiano hasta en sus más pequeños detalles[...]
} 
objetos, vem da tradição antiga. Luiz Costa Lima, diz em seu livro História, Ficção, Literatura, que a metamorfose quase sempre é um castigo, podemos comprovar isso ao citarmos alguns exemplos como Aracne, Narciso, que fazem parte da coletânea de metamorfoses de Ovídeo, poeta romano. Aracne desafia a deusa Athena, chamando-a para uma competição, como forma de punição é transformada em uma aranha. Narciso, era um jovem muito bonito que, ao olhar seu reflexo nas águas de um rio, apaixona-se por si mesmo e tentando alcançar a pessoa que via no reflexo se afoga, mas, como era muito querido pelos deuses, foi transformado em uma flor.No caso do personagem do conto de Murena, podemos supor que a transformação em gato seja um castigo por desistir da vida e começar a viver despreocupadamente.

O gato na literatura é um animal rodeado de simbolismo e misticismo, essa concepção vem desde o antigo Egito e está ligada à deusa Bastet, meia gata e meia mulher, a deusa do pós-morte, os egípcios reverenciavam os gatos, era comum em seus templos a presença dos animais, como também o sacrifício deles como oferenda aos deuses.

As múmias elegantes e bem embaladas dos gatos, muitas vezes com as ligaduras de linho formando padrões geométricos e rostos pintados para dar uma expressão divertida ou humorística, revelam o afeto universal em que a criatura sagrada da deusa era ocupada pelos antigos egípcios. (GEORGE, 1945, p. 46-47). ${ }^{6}$

Já na Idade Média, a figura do gato tomou conotações de animal ligado às forças do mal, podendo até mesmo infligir danos aos seres humanos somente com o olhar.

\begin{abstract}
Gatos respondem apenas quando querem, mantêm seu estilo de vida noturna, têm sua própria agenda, independentemente dos seres humanos. Assim, eles parecem viver em um mundo próprio, inacessível aos humanos, que gostariam de pensar que eles são os mestres de seus animais. No medievo hierárquico - início do mundo moderno, a recusa do gato em obedecer significa que ele falhara em reconhecer o domínio humano sobre animais e, assim, demonstrou seu antagonismo para o homem e Deus.Parecia, portanto, provável que o secreto mundo noturno do gato era presidido pelo Príncipe das Trevas. (ROGERS, 2001, p.45). ${ }^{7}$
\end{abstract}

\footnotetext{
${ }^{6}$ The stylish, well wrapped mummies of the cats, often with the linen bandages forming geometrical patterns and faces painted to give a quizzical or humorous expression, reveal the universal affection in which the goddess's sacred creature was held by the Ancient Egyptians.

${ }^{7}$ Cats respond only when it pleases them, they retain their nocturnal lifestyle, and they pursue their own agenda regardless of humans. Thus they seem to live in a world of their own, inaccessible to
} 
São esses fatores que contribuem para a atribuição de ser místico ao gato, fato que transparece na literatura, como em: "O Gato de Preto", de Edgar Allan Poe, "Os gatos de Ulthar", de Lovecraft, "La orientación de los gatos", de Julio Cortázar, o gato risonho de Alice no país das maravilhas, de Lewis Carroll, assim como outros. No conto de Murena o gato também conota uma figura mística, pois, a partir das impressões do narrador, é descrito como um temido deus, que causa certo desconforto nos hóspedes da pensão.

O gato era grande e robusto, de pelagem cinzenta, com partes de um branco sujo. Dava a impressão de ser um deus velho e degradado, mas que ainda não perdera toda a força para prejudicar os homens. (MURENA, 1940, p. 298).

Devido a sua aparência, no início da narrativa o gato é rechaçado pelos hóspedes da pensão, várias e várias vezes, mas o felino continua a voltar até que, em determinado momento, as pessoas desistem de expulsá-lo e aceitam sua presença no estabelecimento.

No conto de Murena, como em toda narrativa considerada fantástica, podemos perceber a importância da linguagem empregada pelo autor, como elemento crucial na criação da atmosfera do texto, ela cria a verossimilhança, que para Jozef é a condição básica para a existência de qualquer obra de arte.O real e o imaginário implicam a mesma coisa que o verossímil, que transforma o absurdo em significação, dando sentido ao imaginário. (JOZEF, p. 185, 1968).

A linguagem de uma narrativa insólita é diferenciada, ela cria o efeito fantástico, do misterioso no texto, utilizando-se não somente de metáforas, mas elipses e outros recursos metalinguísticos. Remo Ceserani, em seu livro $O$ Fantástico, afirma que existe uma linguagem específica para a literatura fantástica, com uso das potencialidades criativas das línguas, as palavras criam uma nova e diversa realidade, como exemplo ele se vale de Hoffmman e sua novela As aventuras da noite de São Silvestre, na qual o núcleo semântico gerado pela palavra alemã der Haken, traz a imagem perturbadora dos perigos e armadilhas que fragmentam o nosso eu.

the humans that would like to think they are the animals's masters. In the hierarchical medieval early modern world, cat's refusal to obey meant that they failed to recognize the human dominion over animals ordained by providence and thus demonstrated their antagonism to man and God. It therefore seemed likely that the cat's secret nocturnal world was presided over by the Prince of Darkness. 
Ao observarmos o conto de Murena, notamos que nenhum personagem humano é descrito, somente o gato e a pensão. Eles não possuem nomes, são identificados por pronomes de tratamento como: "Ele", "Ela", "Outro", lembrando então de Hoffmman, o fato de não terem seus nomes revelados, não estarem situados no texto, nos ocasiona uma estranheza e uma incerteza, mas também uma maior proximidade com o conto, pois o personagem pode ser qualquer um, alguém normal com problemas em casa que resolve fugir, podendo estar perto do leitor, levando-o a se identificar com o personagem. Bella Jozef diz:

No romance realista, o acontecimento é considerado em relação à condição do indivíduo. A narrativa fantástica inverte esta perspectiva. Dando grande lugar ao insolúvel e ao insólito, apresenta um personagem passivo, porque examina o modo pelo qual as coisas acontecem no universo e tira as consequências para uma definição do estatuto do sujeito.(JOZEF, 1968, p. 183).

A partir dessa perspectiva, o conto fantástico não tem a necessidade de situar o seu personagem geograficamente ou socialmente, diferente dos romances realistas que exploram a identidade do personagem, como é possível ver em Robson Crusoé. Parece-nos que a função dos personagens em certas narrativas insólitas, como é o caso de "O gato", de Murena, é portar-se passivamente frente ao sobrenatural, talvez numa alusão à impotência humana diante de algumas situações da vida.

\section{CONCLUSÃO}

O Fantástico é um gênero textual muito amplo que permite, conforme dito no início desta discussão, uma grande gama de interpretação. Esta forma de escrever nasceu para inquietar o homem, fazê-lo refletir sobre o texto e ir, além disso, fazê-lo refletir por meio do texto, pensando no ambiente sociocultural onde está inserido. Barbosa diz que "A literatura nunca é apenas literatura, o que lemos como literatura é sempre mais - é História, Psicologia, Sociologia. Há sempre mais que literatura na literatura." (BARBOSA, 1994, p. 24).

Quando pensamos nessa frase de João Alexandre Barbosa, podemos ver que o que lemos, sendo ficcional ou não, nos relata uma realidade, toda a leitura tem como base comunicar algo, nos chamar a atenção de eventos, muitas vezes, 
despercebidos no dia a dia. A literatura não é somente um meio de entretenimento, mas um veículo para expressar a realidade, lugar onde o tético e o não-tético se fundem. É exatamente também o que acontece com o insólito, onde os autores se utilizam de um mundo ficcional para denunciar a realidade e os âmagos da existência humana.

\section{REFERÊNCIAS}

BARBOSA, João Alexandre. Literatura nunca é apenas Literatura. São Paulo: FTD, 1994.

CESERANI, Remo. O fantástico. Tradução de Nilton Cezar Tridapalli. Curitiba: Ed. UFPR, 2006.

DJAMENT, Leonora. La vacilación afortunada. H. A. Murena: un intelectual subversivo. Buenos Aires: Colihue, 2007.

FIGUEIREDO, Eunice (org.). Conceitos de literatura e cultura. 2. ed. Niterói: Ed.UFF, Juiz de Fora: Ed.UFJF, 2012.

H. A. MURENA. Disponível em http://www.espaciomurena.com/7310/ Acesso em $27 / 02 / 2018$, às $10: 45$.

HART, George. The Routledge dictionary of Egyptian gods and goddesses. rev. ed. 1986. Library of Congress Cataloging in Publication Data Hart, George, 1945.

JOZEF, Bella. A máscara e o Enigma. São Paulo: Francisco Alves. 1968.

KAFKA, Franz. A metamorfose. São Paulo: Companhia das Letras, 1997.

LIMA, Luiz Costa. História, Ficção, Literatura. São Paulo: Companhia das Letras, 2006.

MURENA, H. A. O gato. In: CASARES, Adolfo Bioy, BORGES, Jorge Luis, OCAMPO, Silvina. Antologia da literatura Fantástica. São Paulo: Cosac Naify, 2013.

TODOROV, Tzvetan. Introdução à literatura fantástica. Tradução Maria Clara Correa Castello. São Paulo: Perspectiva, 2012.

ROAS, David. Teorías de lo fantástico. Madrid: ARCO/LIBROS, 2001.

HART, George. The Routledge dictionary of Egyptian gods and goddesses. rev. ed. 1986. Library of Congress Cataloging in Publication Data Hart, George, 1945.

Data da Submissão: 28/02/2018

Data da Aprovação: 24/07/2018

Revista de Letras JUÇARA, Caxias - Maranhão, v. 02, n. 01, p. 168 - 177, jul. 2018| 177 